\title{
Make me special: Gender differences in consumers' responses to loyalty programs
}

\author{
Valentyna Melnyk • Stijn M. J. van Osselaer
}

Published online: 21 January 2012

(C) The Author(s) 2012. This article is published with open access at Springerlink.com

\begin{abstract}
Current literature on loyalty programs emphasizes the importance of psychological rewards and special treatment. However, it is not clear if male and female customers respond to these incentives in a similar way. We explore the differential effect for female versus male consumers of two psychological rewards that are provided through a loyalty program (a) high status (e.g., Gold membership), and (b) personalization, at different levels of visibility to other consumers. Across three experiments and a field study, we find a coherent pattern of gender differences in the way customers respond to different types of psychological rewards in the context of loyalty programs. The results show that men respond more positively than women to loyalty programs that emphasize status, but only when their higher status is highly visible to others. In contrast, women respond more positively than men to loyalty programs that emphasize personalization, but only for personalization in private settings. We discuss managerial implications for the design of loyalty programs.
\end{abstract}

Keywords Gender differences · Loyalty $\cdot$ Loyalty programs $\cdot$ Personalization $\cdot$ Status

\section{Introduction}

"Rewards that motivate a customer to change his or her behavior have as much to do with psychology as with economics" (O’Brien and Jones 1995 p.80). In the past, company efforts to enhance customer loyalty relied almost exclusively on economic benefits, for example by focusing on monetary rewards such as discounts and free

\footnotetext{
V. Melnyk $(\bowtie)$

Waikato Management School, The University of Waikato, Private Bag 3105, Hamilton 3240, New Zealand

e-mail: vmelnyk@waikato.ac.nz

S. M. J. van Osselaer

Rotterdam School of Management, Erasmus University, T10-07, Burgemeester Oudlaan 50, 3062 PA

Rotterdam, The Netherlands

e-mail: sosselaer@rsm.nl
} 
goods (e.g., free flights). Although such a strategy could result in the desired increase in customer loyalty (van Osselaer et al. 2004; Taylor and Neslin 2005), loyalty programs implementing monetary rewards are usually very costly, and these costs often outweigh the benefits of having such a loyalty program (Leenheer et al. 2007; Meyer-Waarden and Benavent 2009). Therefore, it is not surprising that increasingly more companies turn to psychological benefits (e.g., Gold status, personalized service) as an attractive alternative to stimulate customer loyalty.

Consistent with this trend, recent research suggests that customer loyalty can be strengthened through intimacy (Yim et al. 2008; Hennig-Thurau et al. 2006), or through feelings of superiority (Drèze and Nunes 2009). For example, Kumar and Shah (2004) suggest using psychological rewards (Tier 2 rewards) to "stimulate customers' feelings of belonging and being treated special" (p.323). Similarly, preferential customer treatment was shown to be an important driver of customer loyalty in frequent flyer programs (Rust et al. 2004). However, it is unclear to what extent customer response to those psychological incentives depends on personal characteristics of consumers, in particular, on customers' gender. This is important, because if men and women differ in their response to the same psychological rewards, male and female consumers require different selling approaches and respond differently to actions aimed at enhancing customer loyalty.

Recent findings suggest that customer loyalty of men and women can be inspired by different motives. For example, Melnyk et al. (2009) found that male and female customer loyalties are different in nature. Whereas female consumers tend to be more loyal than males to individuals such as individual service providers, this difference is reversed when the object of loyalty is a group of people, a store, or a company. Noble et al. (2006) found that female loyalty to a local merchant is driven more by social interaction motives, whereas male loyalty to the same firm is driven more by information acquisition motives. Kivetz and Simonson (2003) found that a female's decision to sign up for a loyalty program is influenced more by the idiosyncratic fit of a loyalty program than a male's decision. Thus, it is possible that a reward that is appreciated by one gender may be valued less or even backfire for the other gender. Further, in light of empirical evidence that suggests that men and women respond differently to being observed by others (Eagly and Crowley 1986; Fisher and Dubé 2005; Kleck et al. 1976) the utility of a particular reward may be moderated by its visibility to others.

The goal of our research is to explore the differential effectiveness for female versus male consumers of two psychological rewards that can be provided in the context of a loyalty program: (a) high status (e.g., Gold membership), and (b) personalization-at different levels of visibility to others (widely visible, allowing one to broadcast the psychological reward to other consumers, versus more private). Our research makes several important contributions. First, we contribute to the literature on psychological rewards (Drèze and Nunes 2009; Yim et al. 2008) by investigating the differential response of men and women to the same psychological rewards, including the conditions under which the same reward can lose its effectiveness. Next, we contribute to the growing literature on the role of gender differences in Marketing (Dahl et al. 2009; Klink 2009; Melnyk et al. 2009), by investigating the moderating effect of visibility on desire for status and personalization rewards for both genders. Finally, understanding which rewards motivate male 
and female customers provides powerful and actionable insights for managers, especially because data on gender is commonly available to them.

This article proceeds as follows. We first provide a theoretical background and hypotheses. Then we report the results of three lab studies and a field experiment. We conclude with managerial implications.

\section{Theoretical background}

In Marketing, two commonly employed tools to make customers feel special are the use of membership status and personalization. Regarding status, many loyalty programs subdivide members into different categories with differing levels of benefit. For example, airlines frequently use multiple categories (e.g., Silver member, Gold member, Platinum member) of program membership in which consecutive categories command increasing levels of rewards (e.g., extra frequent flyer miles, upgrade privileges, access to lounges). In addition to economic benefits, the different categories also differ in terms of the social status they accord program participants. This psychological benefit can have a significant effect on participants' behavior (Drèze and Nunes 2009; Grier and Deshpande 2001; Wagner et al. 2009). For example, Drèze and Nunes (2009) demonstrated that being in a specific status tier has a significant effect on choice of a loyalty program that goes beyond differences in material benefits.

Personalized attention is another common psychological reward used in loyalty programs (Barone and Tirthankar 2010; Drèze and Nunes 2009; Lacey et al. 2007; Yim et al. 2008). For example, loyalty programs for cosmetics often send a card on program members' birthdays. At upscale hotels as well as in mom-and-pop stores on Main Street, great effort is invested in addressing loyalty program members by their family name instead of using the generic Sir or Madam, or in learning members' personal preferences.

Both status and personalization can be provided in more versus less visible ways. For example, elite status in an airline's program can be broadcast, for all to see, using gold-colored luggage tags and separate access to airplanes and ticket counters. Elite status can also be enjoyed more privately and discretely (e.g., concierge service through elite credit cards; private style advisor for Gold members of an upscale clothing chain). Similarly, personalization can be highly visible (e.g., when a flight attendant loudly welcomes a member by name in a crowded airplane or a restaurant guest is serenaded on her birthday) or much more privately (e.g., a card sent to a member's home to mark his or her birthday).

The effectiveness of status and personalization, and the way this effectiveness depends on visibility, may be contingent on the customer's gender. Previous research suggests that men are more likely than women to change their behavior when they are visible to others. For example, Eagly and Crowley (1986), in a meta-analysis on helping behavior, found that men are especially more helpful than women in the presence of other people. Similarly, Fisher and Dubé (2005) demonstrated that males reported a different viewing experience and different attitude towards an advertisement depending on whether they watched it alone or with another male. The authors did not find these differences for females. These studies suggest a possibility that men 
might be more sensitive than women to visibility of loyalty program rewards to others. However, it seems equally possible that desirability of only particular types of reward is enhanced by their visibility to others.

Earlier theories portrayed men as more individualistic relative to more social females, with men exhibiting more independent and women more interdependent self-construal (Cross and Madson 1997; Markus and Kitayama 1991). In contrast, recent findings support a view of male customers' collective interdependence relative to females' relational interdependence (Baumeister and Sommer 1997; Melnyk et al. 2009). That is, men care (more than women) about relationships with larger groups whereas women care (more than men) about individual, personal relationships. Success in groups depends highly on group status (more than in personal relationships). Citing evolutionary theories, Baumeister and Sommer (1997) hypothesized that men are more concerned about their status than women are: "the achievement of dominant status has long been a way for men (but not for women outside of the domestic circle) to achieve power over others" (p. 39). This view is also consistent with the sexual strategies theory, which suggests that the best strategy for men to win in both intersexual and intrasexual competition is to display their resources, i.e., status (Buss 1988; Buss and Schmitt 1993; Tooke and Camire 1991). The latter observation raises another important issue, namely, it is important that this status is known to all members of the, often quite large, group. Communicating status to groups is usually not easily achieved through one-on-one interactions. Thus, status for men may have little value unless it is highly visible, allowing status to be communicated one-to-group.

In contrast to men, high status has been a relatively less desirable characteristic for a woman to be socially accepted (Baumeister and Sommer 1997; Baumeister and Vohs 2004; Buss and Schmitt 1993). In a comprehensive study across 70 different countries, Schwartz and Rubel (2005) found that men and women differ fundamentally in the values and motives that drive their behavior. For example, men value social status, prestige, dominance and achievement more than women do. Instead of group status, women focus more than men on individual, personal relationships (Baumeister and Sommer 1997). In these relationships, social status (or at least the type of social status conveyed by the elite status in loyalty programs) is less important, as is broadcasting such status to a group. Thus, for female customers it is important to be recognized as an individual person, with a name, a birthday, and her own idiosyncratic preferences rather than as a generic Gold member. In addition, it is less important that the personalization is visible to other people outside the dyad made up by the female customer and the firm, because women are less concerned about broadcasting their achievements to the group. In fact, visibility of personalization may even backfire for women because visibility reduces intimacy, which is desirable for women (Baumeister and Sommer 1997). Moreover, women were shown to be generally more inclined to exhibit modesty, especially in situations with a possibility of hurting other people's feelings (Cross and Madson 1997). In sum, we predict that:

H1: Men respond more positively than women to loyalty programs that emphasize status, but only when their higher status is highly visible to others.

$\mathrm{H} 2$ : Women respond more positively than men to loyalty programs that emphasize personalization, but only for personalization in private settings. 


\section{Preliminary studies}

The goal of the preliminary studies was to start exploring parts of the hypothesized three-way interaction pattern (between reward type, gender, and reward visibility) in a controlled lab setting. In studies 1 and 2, we explored whether male customers (relative to female customers) tend to respond more positively to more visible (versus less visible) status rewards. In study 3, we explored whether female customers (relative to male customers) respond more positively to more private, personalized rewards than to equally private, but less personalized rewards. The main study (study 4) tests the full three-way interaction pattern in a field setting.

\subsection{Study 1}

Method Study 1 explored whether males respond more positively than females to loyalty program elements that provide more visible status (versus less visible status). Participants (27 female and 28 male undergraduate students) read the following scenario:

Imagine you want to travel around the world. Imagine there are two airlines that sell such a ticket for the same price. Both of these airlines have loyalty programs. According to the rules of both airlines' loyalty programs, buying an around-theworld ticket would immediately qualify you to become a Gold-level frequent flyer (because you need to fly 25,000 miles to qualify for Gold-level memberships and flying around the world gives you more than 25,000 miles). Among other advantages, both airlines offer free name-and-address tags for their Goldmembers' luggage. Airline A provides plain white tags to its Gold-members, which do not identify you publicly as a member with Gold status. Airline B provides gold-colored tags, which do reflect your Gold status. Apart from the difference in the color of the luggage tags both airlines and their loyalty programs provide the same benefits, prices, privileges, and service to their Gold-level members.

Participants were asked which airline they would choose on a seven-point scale ranging from 1 (definitely $A$ [with the white tag]) to 7 (definitely $B$ [with the goldcolored tag7). Next, participants answered a manipulation check question: "Which of the two airlines makes your Gold-member status most visible to other people?" (on a seven-point scale from $1=$ definitely $A ; 4=$ equally much; 7 =definitely $B$ ). As intended, participants thought that the airline providing gold-colored tags made membership status most visible $\left(M_{\text {visibility }}=6.60\right.$, significantly different from the neutral midpoint of $4 ; t(54)=20.20, p<0.001)$. This difference did not significantly depend on gender $(t(53)=-0.34, p>0.10)$.

Results Consistent with our expectation that male customers respond more positively to more visible loyalty program status than female customers, we found that males indicated a higher average likelihood of choosing the airline with the gold-colored $\operatorname{tags}\left(M_{\text {male }}=5.29\right)$ than females $\left(M_{\text {female }}=3.59 ; t(53)=3.50, p=0.001\right)$. Thus, results in study 1 supported the prediction that males are more likely than females to choose a loyalty program that allows for a visible display of their Gold-member status. 


\subsection{Study 2}

Method Study 2 explored the generalization of the results from Study 1. Participants (50 female and 58 male undergraduate students) were randomly assigned to one of the two conditions. Participants in the low-visibility condition read the following scenario:

Imagine that the supermarket you usually shop at offers a loyalty program. After you accumulate 1,000 Euros of purchases at the supermarket within a 6month period, you become a Gold-level member of the loyalty program. As a Gold-member, you are entitled to use a special super-fast express checkout lane. To allow the express lane cashier to see whether a shopper is entitled to express lane checkout, Gold-level members present the cashier with their Gold-level membership card.

In the high-visibility condition, the latter sentence was replaced with the following one: "To allow the express lane cashier to see whether a shopper is entitled to express lane checkout, Gold-level members shop with a special Gold-level shopping basket or cart, which has a bright gold-colored handle." After reading the scenario, participants indicated the likelihood that they would start spending more in this store to become a Gold member as soon as possible (on a seven-point scale from $1=$ very unlikely to $7=$ very likely). To check the visibility manipulation, participants were asked: "How easy is it for other customers to see that you are a Gold member?" (on a seven-point scale from $1=$ very invisible to $7=$ very visible). As intended, average ratings of Goldmembership visibility to other customers were higher in the high-visibility condition $\left(M_{\text {high-visibility }}=5.02\right)$ than in the low-visibility condition $\left(M_{\text {low-visibility }}=3.45 ; t(106)=\right.$ $-4.83, p<0.001)$. This difference did not significantly depend on gender $(F(1,104)=$ $0.01, p>0.10$ ). To control for alternative explanations involving negative emotions towards Gold status members, we measured the following negative emotions: envy, jealousy, frustration, anger, and irritation using items adopted from Richins (1997). We used the average across those emotions as a covariate (Cronbach's $\alpha=0.88$ ). Neither negative emotions $(F(1,102)=0.84, p>0.10)$ nor its interaction with gender $(F(1,102)=0.13, p>0.10)$ had a significant relationship with likelihood to start spending more. Thus, alternative explanations in terms of negative emotions towards Gold members can be ruled out.

Results We conducted an ANOVA with perceived likelihood of spending more to become a Gold member as the dependent variable, and visibility, gender, and their interaction and as the independent variables. We also included negative emotions and their interaction with gender as covariates. The results confirm the hypothesis that male consumers respond more positively than female consumers to more visible signs of status. Whereas the main effects of gender $(F(1,102)=0.02, p>0.10)$ and visibility $(F(1,102)=0.04, p>0.10)$ were not significant, their interaction was $(F(1,102)=5.77, p<0.05)$.

Follow-up contrasts indicated that for males, increased visibility led to higher likelihood ratings of spending more to become a Gold member $\left(M_{\text {males/high-visibility }}=\right.$ $3.30, M_{\text {males/low-visibility }}=2.42, t(44)=-1.86, p<0.05$; all follow-up, simple-effect contrasts in this manuscript are one-tailed). For females, increased visibility had a marginally significant negative effect on the perceived likelihood to start spending 
more $\left(M_{\text {females } / \text { high-visibility }}=2.31, M_{\text {females/low-visibility }}=3.00, t(48)=1.58, p=0.06\right)$. Thus, the effect of visibility of status for females was smaller than for males, even to the extent that there was a marginally significant reversal of the effect found for males. As expected, the difference for the high-visibility condition between men and women was significant $(t(51)=-1.95, p<0.05)$, confirming that men respond more positively than women to loyalty programs that provide widely visible status.

Thus, Study 2 provided additional support for the idea that males and females differ in their sensitivity to visible status rewards. Consistent with the idea that men only value status more than women if that status is visible, the absence of a significant gender main effect illustrates that male participants are not necessarily more sensitive to status than women overall. Only when the status was visible, male customers were more likely than female customers to start spending more to reach it.

\subsection{Study 3}

Method Study 3 explored whether women are more responsive to loyalty program personalization than men when personalization is relatively private. Participants (25 female and 27 male undergraduate students) read the following scenario:

Imagine you want to become a member of a DVD/video rental store's loyalty program. You have two options, store A and store B. Both stores offer the same discount to loyalty program members: half-price movie rentals during one 2-week period per year. Store A implements this discount in the following way: the two half-price weeks are randomly chosen by the store (a member receives information about them at the beginning of the year). Store B implements this discount in the following way: the two half-price weeks are the two weeks subsequent to the member's birthday (a member receives information about them at the beginning of the year). Apart from these differences, the stores and their loyalty programs are exactly the same. To become a member of any of the two stores you need to fill in a form, indicating your name, home address, and date of birth. Thus, both stores require you to fill out exactly the same information. Both stores have about the same assortment and same prices. If you visit the store regularly, the overall material benefits are approximately the same in both stores.

Participants indicated which of the two loyalty programs they would join (on a sevenpoint scale: $1=$ definitely $A ; 7=$ definitely $B$ ). As a manipulation check, participants indicated "Which store gives you the most personal attention?" (same scale as above). As intended, participants perceived store B to give more personal attention $\left(M_{\text {storeB }}=\right.$ 5.73 , which is significantly different from the neutral midpoint of $4 ; t(51)=11.12, p<$ 0.001). We also tested for the following potential alternative explanations. Three questions assessed the importance of privacy concerns to the participant and the extent to which each of the stores was seen to infringe upon its members' privacy. Next, we used a five-item arousal-seeking scale, to probe for attitudes toward predictability (adopted from Steenkamp and Baumgartner 1992).

Results As predicted, female participants had a stronger preference to join the personalizing store's loyalty program than male participants $\operatorname{did}\left(M_{\mathrm{female}}=5.44 \mathrm{vs}\right.$. 
$\left.M_{\text {male }}=3.96, t(50)=3.36, p=0.001\right)$. The potential alternative explanations can be ruled out. Participants perceived the personalizing store $\left(M_{\text {storeB }}=2.88\right)$ to be infringing upon customers' privacy more than the randomizing store $\left(M_{\text {storeA }}=2.52 ; t(51)=-2.02, p<\right.$ $0.10)$. Importantly, males and females did not differ in the above assessment of the stores' privacy infringement (main effect of gender: $F(1,50)=0.90, p>0.10$, interaction effect of gender and store: $F(1,50)=0.034, p>0.10)$. Yet, with respect to the privacy concerns variable, females were significantly more concerned with privacy than males $\left(M_{\text {female }}=5.64 ; M_{\text {male }}=4.22 ; t(50)=3.80, p<0.001\right)$. Thus, if anything, the main result that females prefer the personalizing store is opposite to what one would expect based on a privacy explanation. Another potential alternative explanation is that men may appreciate uncertainty more than women, and therefore prefer the random 2-week discount period over the one that is known. This explanation can be ruled out in this case because there is no significant gender difference in preference for uncertainty vs. certainty $\left(M_{\text {female }}=3.54 ; M_{\text {male }}=3.81 ; t(50)=-0.95, p>0.10\right)$. Thus, the results in Study 3 suggest that in a relatively private context, female consumers are more responsive to loyalty programs that take individual, personal characteristics of their members into account.

\section{Separating visibility, status, and personalization}

Although the findings in Studies 1 through 3 supported the idea that men are more responsive to the status rewards that are more visible, while women respond more to personalization rewards in a relatively private context, the three studies did not allow us to distinguish some main effects from interaction effects. Therefore, the next study was designed to simultaneously examine preference for personalization and status rewards at different levels of visibility by orthogonally assessing visibility and reward type (status versus personalization). Furthermore, whereas Studies 1 through 3 were lab experiments that were designed to achieve high internal validity, they also involved hypothetical scenarios that may raise concerns about external validity and possible demand effects. Therefore, study 4 was designed as a field experiment with real choices in a realistic context that should not be prone to demand effects.

Next, although the Netherlands-based student samples used in the scenario studies 1-3 consist of real consumers who fly on planes, buy groceries, and rent DVDs, we wanted to check the generalization of our effects to a general population sample in another country, New Zealand. Finally, to address a potential alternative explanation of study 3 that women care more about birthdays (regardless of personalization) than men, we used a different context in study 4. Namely, we looked at respondents' preferences for placing their names or program membership status on more versus less visible products.

\subsection{Study 4: field experiment}

The goal of study 4 was to test the extent to which customers appreciate personalized and status rewards at different levels of visibility with general population participants and real-world consequences. 
Procedure The experiment was 2 (visibility: high [t-shirt] vs. low [towel]) $\times 2$ (gender: male vs. female) $\times 2$ (reward type: status [Platinum Member] vs. personalized attention [customer's name]). The first independent variable was manipulated betweenparticipants. The second was measured. The third was manipulated within-participant. One hundred and twenty members (60 females; 60 males) of a popular gym (who were randomly picked by the gym and who were members for at least 5 years) were contacted by a letter using the gym's letterhead. They were randomly assigned to one of the two versions of the letter (t-shirt vs. towel). In the letter, members were thanked for their loyalty and were told that as a token of appreciation, they were to receive a Platinum Membership Card for the gym. Next, participants in the high-visibility condition were informed they had been selected to enter in a draw to win a t-shirt. Participants in the low-visibility condition were informed they had been selected to enter in a draw to win a towel. In both conditions, they were (truthfully) informed that they had about a 50\% chance to win. To enter the draw the participants were asked to fill out a form, where they indicated whether they wanted their first name to be printed on the t-shirt (towel) using a seven-point scale ( $1=$ definitely would not like to $7=$ definitely would like). Participants who wanted their first name printed on the item were asked how they would like the name to be spelled. Next, participants indicated if they wanted the phrase "Platinum Member" to be printed on the t-shirt (towel) using the same seven-point scale. Participants were told their choices had no effect on the likelihood of winning. Ninetyfour completed questionnaires were returned (46 females; 48 males; 80\% response rate). Participants did not have to choose between printing their name or Platinum Member on the t-shirt. It was possible to print one, neither, or both. The gym has genuinely run the draw and given free t-shirts and towels to the winning members.

Results An omnibus ANOVA yielded the expected three-way interaction between gender, visibility, and reward type $(F(4,178)=4.52, p<0.01)$. This three-way interaction shows that our findings cannot be attributed fully to a male preference for visibility irrespective of what status is visible or to a female preference for personalization regardless of its visibility. To further interpret the results, we conducted two separate ANOVA's with (1) preference to have their name printed and (2) preference to have Platinum Member printed as dependent variables.

The ANOVA with the degree of preference for the first name to appear on the product (i.e., preference for personalized attention) as the dependent variable and visibility (towel vs. t-shirt), gender, and their interaction as independent variables yielded the predicted effects. There was a significant interaction between gender and visibility $(B=-1.89, F(1$, $94)=4.59, p<0.05)$ as predicted. That is, women had a stronger preference than men for their first name to be displayed on the towel $(t(43)=-2.14, p=0.02)$, but not for their names to be displayed more publicly on the t-shirt $(t(47)=0.84, p>0.10)$. The means are displayed in Table 1 . Results showed no main effect of gender $(F(1,94)=$ $0.99, p>0.10$ ), implying that women did not express a stronger preference for their names to be displayed across both towel and t-shirt conditions. There was a significant main effect of visibility, thus, overall, participants preferred their name to appear on the towel rather than on the t-shirt $(B=-3.89, F(1,94)=36.49, p<0.001)$.

The ANOVA with the degree of preference for "Platinum member" (i.e., a sign of high status) to appear on the product as dependent variable and visibility (towel vs. t-shirt), gender, and their interaction as independent variables also yielded the expected effects. 
Table 1 Results of study 4 (field experiment)

Reported are means on a seven-point scale $(1=$ definitely would not like; $7=$ definitely would like)
Gender Preference for display of Preference for display of customer name on:

"Platinum member" on:

Towel T-shirt Towel T-shirt

\begin{tabular}{lllll}
\hline Female & 5.96 & 2.33 & 4.68 & 3.67 \\
Male & 4.57 & 2.84 & 3.61 & 4.92
\end{tabular}

There was a significant interaction in the expected direction between gender and visibility $(B=-2.33, F(1,94)=4.11, p<0.05)$, showing that males had a marginally significant stronger preference for broadcasting their platinum status on a t-shirt than females $(t$ $(47)=1.58, p=0.06$ ). Further confirming the idea that males are only more interested than females in status if this status is easily visible to the group, males did not show a higher preference to mention the platinum status on the towel than females. In fact, we found a marginally significant effect in the opposite direction $(t(43)=-1.30, p=$ $0.10)$. Results showed no main effect of gender $(F(1,94)=0.03, p>0.10)$, thus, men did not express a stronger preference for their status to be displayed across both towel and t-shirt conditions. This result again suggests that men are specifically interested in a highly visible display of status. They seem to lose interest as soon as status becomes more private. There was also no significant main effect of visibility $(F(1,94)=0.07$, $p>0.10$ ), suggesting that overall participants did not show a higher preference for the platinum status to appear on the t-shirt versus towel. Hence, it is the interaction between visibility and gender that drives the effect for platinum status display.

In the field experiment we have tested $\mathrm{H} 1$ and $\mathrm{H} 2$ using actual customers of a gym and separating the effects of status, visibility and personalization. Consistent with our studies $1-3$, we find that men tend to be more sensitive (than women) to rewards that enhance their social status in a visible way. In contrast, women (compared to men) prefer rewards that provide personalized attention in a more discrete way. Importantly, the results in Study 4 also confirmed that male preference for highly visible status rewards cannot be attributed to a main effect preference for visibility. Likewise, results in this study confirmed that female preference for less visible personalized rewards cannot be attributed to an overall preference for personalization regardless of visibility. Thus, the results indicate that men respond more positively than women to loyalty programs that emphasize status, but only when their higher status is highly visible to others. In contrast, women respond more positively than men to loyalty programs that emphasize personalization, but only for personalization in private settings.

\section{General discussion}

Across three experiments and a field study, we find a coherent pattern of gender differences in the way customers respond to different types of psychological rewards in the context of loyalty programs. Consistent with the idea that women are geared more than men toward one-to-one, personal relationships, we find that rewards that make a loyalty program more like a one-to-one relationship appeal particularly to female customers, but only in private settings. This effect is found even when the 
reward elements, such as timing a reward based on a member's birthday or personalizing an item with the customer's first name, bear only a shallow resemblance to a real personal relationship. Apparently, the combination of communicating program rewards in a relatively private way and personalizing the reward such that the customer is treated as an individual person (instead of as a member of a category or group) is close enough to a personal relationship to be effective for women. Also in line with previous findings about males' focus on group relationships, we find that male customers respond particularly well to rewards that facilitate one-to-group communication of males' position in a group. That is, men respond more positively to rewards that broadcast their status by making that status easily visible to others.

Our work has several contributions. First, we contribute to the literature on customer loyalty and loyalty programs (Dorotic et al. 2010; Drèze and Nunes 2009; Palmatier et al. 2009; Wagner et al. 2009) by showing empirically that male and female customers differ in their responses to psychological rewards frequently used by loyalty programs, such as personalized attention and status. Second, our results contribute to the growing interest in investigating the role of gender differences in the recent marketing literature (Dahl et al. 2009; Fisher and Dubé 2005; Klink 2009; Melnyk et al. 2009). We demonstrate that men and women respond to different psychological rewards: while women are more sensitive to discrete personalized attention, men are more sensitive to psychological rewards that allow them a more visible display of their high status. Finally, our findings have implications for the study of gender identity (Baumeister and Sommer 1997; Cross and Madson 1997). We show that differences between the genders are not only revealed in big domains such as a focus of social life on close individual relationships versus on groups, but that these gender differences even exhibit themselves in response to very subtle differences in treatment (e.g., simply framing a loyalty reward in a more personal way by timing it in terms of a member's birthday). Thus, self-construal differences between males and females may pervade customers' behavior in a much more fundamental and widespread way than we might have expected.

\subsection{Managerial implications}

Our findings have clear and direct implications for the design of loyalty programs. Loyalty program managers should endeavor to make both male and female program participants feel special, but they should do so in different ways. When designing a loyalty program where a large share of customers are female (e.g., female apparel stores, cosmetics), a loyalty program's design elements should signal the recognition of a female consumer as an individual person in a way that is not ostentatiously displayed to a greater audience. The latter effect can be utilized by giving the relationship between a female consumer and a firm a more personal feel, even if the level of personalization is quite superficial (e.g., via a birthday postcard, personalized samples). Thus, personalizing communication and benefits to give a program a more personal, one-to-one look and feel should particularly benefit loyalty program response by female customers. Thus, managers should make females feel special by privately recognizing them as an individual person ("How are you Kate?").

In contrast, male response to loyalty programs should be enhanced by making high levels of status widely visible. Whereas Gold-colored luggage labels and visibly 
separated elite check-in lines may not appeal to many women, male consumers may find them an excellent way to communicate their status to the group. Therefore, loyalty programs targeted at male consumers (e.g., male apparel, fishing gear, gadgets) should incorporate status and visibility. In particular, company managers should help their male customers broadcast their special group status ("Look everybody, he's a Gold member!").

We would also like to stress that these recommendations apply most clearly to companies that target one gender. For companies that target both genders, the advantages of different psychological rewards for male versus female customers documented in this article should be traded off against the drawbacks of such customized treatment. For example, the two groups may resent being treated differently solely on the basis of gender (Feinberg et al. 2002).

\subsection{Limitations and future research}

Demand effects are an ever-present concern in experimental studies. According to Shimp et al. (1991) all of the following three conditions must be satisfied for a participant to be demand biased. "First, the subject must encode a demand cue that would alert him or her to the research hypothesis. Second, s/he must discern the correct research hypothesis or guess another hypothesis that is incidentally correlated with the true research hypothesis. Third, s/he must act on the hypothesis by conforming to a certain role that leads to biased responses on dependent variable measures." (Shimp et al. 1991, p. 274).

With respect to condition 1 , in the first three studies, subjects were aware of one possible demand cue: the gold tag vs. white tag (Study 1), the gold-level membership and gold-handled shopping basket (Study 2) or the deal organized around birthday rather than randomly (Study 3). However, it is unlikely that respondents were alerted to the other factor in our design, gender, which was manipulated betweenparticipants. This also made it very unlikely that participants would be able to guess that the study was about male vs. female differences with regard to responses to characteristics of the loyalty program (condition 2) or that participants would act on such a hypothesis (condition 3). We took care that gender, which was always varied between-participants, was never made salient in any of the studies. Throughout the paper, we selected gender neutral domains that would be equally likely used by men and women. In studies 1-3 we made sure that participants took part in the study in mixed gender groups in contexts in which mixed gender is normal. Next, in studies 1-3 we asked participants an open-ended question about the purpose of the experiment and none of them reported anything related to gender. In the field experiment (study 4), participants were not aware they participated in a study at all. Hence, we believe the conditions for a demand effect explanation were not met in any of the studies.

Further evidence against demand effects in any of the studies is provided by the fact that consistent effects were found across studies that might seem to vary in terms of their vulnerability to demand effects. If demand would have played a role, we should have found different patterns of results between studies depending on the demandvulnerability of specific studies. Across a mixture of methods (two within-participant lab experiments, one between-participants lab experiment, and one between-participants 
field experiment), four completely different participant pools from two different countries, and multiple product categories we always found consistent results.

Beyond experimental demand, it is of course possible that participants' evaluations and behavioral intentions in the first three studies were influenced by gender roles, even when gender was not salient to them. One might consider this a form of socially desirable responding. However, there is every reason to believe real behavior is also influenced by those gender roles in exactly the same direction. Thus, it is likely that real behavior is influenced by social desirability as well. Therefore, our results should still be indicative of real behavior. This conclusion is consistent with our field study, which measures actual behavior in a natural, non-experimental context.

Next, although (a) scenario studies are frequently used in our domain (e.g., Kivetz 2005; Kivetz and Simonson 2002, 2003; Melnyk et al. 2009), (b) empirical evidence (e.g., Chandon et al. 2005) suggests that the directions of behavioral intentions are good predictors of the directions of actual behavior, and (c) we included a field study featuring real choice behavior, intentions may differ from actual behavior. Thus, future research should do more to investigate the effect of psychological rewards on actual behavioral (e.g., share of wallet, expenditures) based on, for example, household panel data.

Finally, we have demonstrated that men are more sensitive to visible status rewards, while women are more sensitive to the private personalized rewards in a loyalty program setting. It would be interesting to see if these effects generalize to other settings (e.g., one-shot promotional offers that treat customers as individuals). Another factor of potential interest is the role of identity salience. We found strong gender differences despite the fact that nothing in our scenarios or main measures highlighted gender (i.e., gender identity salience was low). It is possible that the effects would be even stronger if gender identity is more salient (Forehand et al. 2002; Reed 2004; Wooten 1995). We hope our research opens new opportunities for further exploration of the role of gender in response to marketing communication.

Acknowledgments The authors would like to thank Harald van Heerde and Tammo Bijmolt for their helpful comments.

Open Access This article is distributed under the terms of the Creative Commons Attribution Noncommercial License which permits any noncommercial use, distribution, and reproduction in any medium, provided the original author(s) and source are credited.

\section{References}

Barone, M. J., \& Tirthankar, R. (2010). Does exclusivity always pay off? Exclusive price promotions and consumer response. Journal of Marketing, 74(2), 121-132.

Baumeister, R. F., \& Sommer, K. L. (1997). What do men want? Gender differences and two spheres of belongingness: Comment on Cross and Madson. Psychological Bulletin, 122(1), 38-44.

Baumeister, R. F., \& Vohs, K. D. (2004). Sexual economics: Sex as female resource for social exchange in heterosexual interactions. Personality and Social Psychology Review, 8(4), 339-363.

Buss, D. M. (1988). The evolution of human intrasexual competition tactics of mate attraction. Journal of Personality and Social Psychology, 54(4), 616-628.

Buss, D. M., \& Schmitt, D. P. (1993). Sexual strategies theory: A contextual evolutionary analysis of human mating. Psychological Review, 100(2), 204-232. 
Chandon, P., Morwitz, V. G., \& Reinartz, W. J. (2005). Do intentions really predict behavior? Selfgenerated validity effects in survey research. Jouranl of Marketing, 69(2), 1-14.

Cross, S. E., \& Madson, L. (1997). Models of the self: Self-construals and gender. Psychological Bulletin, 122(1), 5-37.

Dahl, D. W., Sengupta, J., \& Vohs, K. D. (2009). Sex in advertising: Gender differences and the role of relationship commitment. Journal of Consumer Research, 36(2), 215-231.

Dorotic, M., Fok, D., Verhoef, P. C., \& Bijmolt, T. H. A. (2010). Do vendors benefit from promotions in a multi-vendor loyalty program? Marketing Letters. doi:10.1007/s11002-010-9128-8.

Drèze, X., \& Nunes, J. C. (2009). Feeling superior: The impact of loyalty program structure on consumers' perceptions of status. Journal of Consumer Research, 35(6), 890-905.

Eagly, A. H., \& Crowley, M. (1986). Gender and helping behavior: A meta-analytic review of the social psychological literature. Psychological Bulletin, 100(3), 283-308.

Feinberg, F., Krishna, A., \& Zhang, J. Z. (2002). Do we care what others get? A behaviorist approach to targeted promotions. Journal of Marketing Research, 39(3), 277-291.

Fisher, R., \& Dubé, L. (2005). Gender differences in responses to emotional advertising: A social desirability perspective. Journal of Consumer Research, 31(4), 850-858.

Forehand, M. R., Deshpande, R., \& Reed, A., II. (2002). Identity salience and the influence of differential activation of the social self-schema on advertising response. Journal of Applied Psychology, 87(6), 1086-1099.

Grier, S. A., \& Deshpande, R. (2001). Social dimensions of consumer distinctiveness: The influence of social status on group identity and advertising persuasion. Journal of Marketing Research, 38(2), 216224.

Hennig-Thurau, T., Groth, M., Paul, M., \& Gremler, D. D. (2006). Are all smiles created equal? How emotional contagion and emotional labor affect service relationships. Journal of Marketing, 70(3), 5873.

Kivetz, R. (2005). Promotion reactance: The role of effort-reward congruity. Journal of Consumer Research, 31(March), 725-736.

Kivetz, R., \& Simonson, I. (2002). Earning the right to indulge: Effort as a determinant of customer preferences toward frequency program rewards. Journal of Marketing Research, 39(2), 155-170.

Kivetz, R., \& Simonson, I. (2003). The idiosyncratic fit heuristic: Effort advantage as a determinant of consumer response to loyalty programs. Journal of Marketing Research, 40(4), 454-467.

Kleck, R. E., Vaughan, R. C., Cartwright-Smith, J., Vaughan, K. B., Colby, C. Z., \& Lanzetta, J. T. (1976). Effects of being observed on expressive, subjective and physiological responses to painful stimuli. Journal of Personality and Social Psychology, 34(6), 1211-1218.

Klink, R. R. (2009). Gender differences in new brand name response. Marketing Letters, 20, 313-326.

Kumar, V., \& Shah, D. (2004). Building and sustaining profitable customer loyalty for the 21 st century. Journal of Retailing, 80(4), 317-329.

Lacey, R., Suh, J., \& Morgan, R. M. (2007). Differential effects of preferential treatment levels on relational outcomes. Journal of Service Research, 9(3), 241-256.

Leenheer, J., van Heerde, H. J., Bijmolt, T. H., \& Smidts, A. (2007). Do loyalty programs really enhance behavioral loyalty? An empirical analysis accounting for self-selecting members. International Journal of Research in Marketing, 24(1), 31-47.

Markus, H. R., \& Kitayama, S. (1991). Culture and the self: Implications for cognition, emotion, and motivation. Psychological Review, 98, 224-253.

Melnyk, V., van Osselaer, S. M. J., \& Bijmolt, T. H. (2009). Are women more loyal customers than men? Gender differences in loyalty to firms and individual service providers. Journal of Marketing, 73(4), 82-96.

Meyer-Waarden, L., \& Benavent, C. (2009). Grocery retail loyalty program effects: Self-selection or purchase behavior change? Journal of the Academy of Marketing Science, 37(3), 345-358.

Noble, S. M., Griffith, D. A., \& Adjei, M. T. (2006). Drivers of local merchant loyalty: Understanding the influence of gender and shopping motives. Journal of Retailing, 82(3), 177-188.

O’Brien, L., \& Jones, C. (1995). Do rewards really create loyalty? Harvard Business Review, 73(3), 75-82.

Palmatier, R. W., Burke, J. C., Bechkoff, J. R., \& Kardes, F. R. (2009). The role of customer gratitude in relationship marketing. Journal of Marketing, 73(5), 1-18.

Reed, A., II. (2004). Activating the self-importance of consumer selves: Exploring identity salience effects on judgments. Journal of Consumer Research, 31(2), 286-295.

Richins, M. L. (1997). Measuring emotions in the consumption experience. Journal of Consumer Research, 24(2), 127-146. 
Rust, R. T., Lemon, K. N., \& Zeithaml, V. A. (2004). Return on marketing: Using customer equity to focus marketing strategy. Journal of Marketing, 68(1), 109-127.

Schwartz, S. H., \& Rubel, T. (2005). Sex differences in value priorities: Cross-cultural and multimethod studies. Journal of Personality and Social Psychology, 89, 1010-1028.

Shimp, T. A., Hyatt, E. M., \& Snyder, D. J. (1991). A critical appraisal of demand artifacts in consumer research. Journal of Consumer Research, 18(3), 273-283.

Steenkamp, J. -B. E. M., \& Baumgartner, H. (1992). The role of optimum stimulation level in exploratory consumer behavior. Journal Consumer Research, 19(3), 434-448.

Taylor, G. A., \& Neslin, S. A. (2005). The current and future sales impact of a retail frequency reward program. Journal of Retailing, 81(4), 293-305.

Tooke, W., \& Camire, L. (1991). Patterns of deception in intersexual and intrasexual mating strategies. Ethology and Sociobiology, 12(5), 345-364.

Van Osselaer, S. M. J., Alba, J. W., \& Manchanda, P. (2004). Irrelevant information and mediated intertemporal choice. Journal of Consumer Psychology, 14(2), 257-270.

Wagner, T., Hennig-Thurau, T., \& Rudolph, T. (2009). Does customer demotion jeopardize loyalty? Journal of Marketing, 73(3), 69-85.

Wooten, D. B. (1995). One-of-a-Kind in a full house: Some consequences of ethnic and gender distinctiveness. Journal of Consumer Psychology, 4(3), 205-224.

Yim, C. K. B., Tse, D. K., \& Chan, K. W. (2008). Strengthening customer loyalty through intimacy and passion: Role of customer-firm affection and customer-staff relationships in services. Journal of Marketing Research, 45(6), 741-756. 